\title{
Assessing Life Long Learning Utilizing Coop Work Term Report
}

\author{
Reem Roufail \& Carolyn G. MacGregor \\ Department of Systems Design Engineering, \\ University of Waterloo \\ rroufail@uwaterloo.ca \\ carolyn.macgregor@uwaterloo.ca
}

\begin{abstract}
CEAB introduced graduate attributes $(G A)$ as a tool to measure the performance of an engineering institute in delivering its engineering programs. The $12^{\text {th }}$ attribute is Life Long Learning (LL), which is defined as the student's ability to identify and address their own educational needs. A student's reaching out to technical references, away from an academic setting, is identified as a measuring tool for $L L$. As a pilot study, the technical references evaluated were extracted from a sample of 12 artifacts - $4^{\text {th }}$ year work-term technical reports submitted as a component of co-operative education (co-op).

To measure LL, a categorical metric to assess quality of cited sources was used to assess student competence in selecting credible technical information. All students included at least one technical reference in the design/analysis section (Technical Reference, TR); with most students using a mix of TR quality. Only 1/3 of students had average TR quality scores that met or exceeded the benchmark of 3.0. There may be a relationship between the type of work sector experienced and quality of references used.

The pilot study suggests that using a quality metric for technical references within student documents has potential to assess lifelong learning at both the individual and cohort level. Results reinforce the need to educate and reiterate to engineering students the importance of credibility of the source of information over convenience.
\end{abstract}

Keywords: Life Long Learning; Graduate Attribute; Technical References; Credible References

\section{INTRODUCTION}

CEAB introduced graduate attributes (GA) as a tool to measure the performance of an engineering institute in delivering its engineering programs. GA can also be utilized as a means of program self-assessment and continual improvement. The $12^{\text {th }}$ attribute, according to $\mathrm{CEAB}$ is lifelong learning (LL) defined as "An ability to identify and to address their own educational needs in a changing world in ways sufficient to maintain their competence and allow them to contribute to the advancement of knowledge" [2]. Few attempts have been made to measure LL by gathering student self-report data.
For example, Kirby et. al (2010) [4], created a 14-item Lifelong Learning Questionnaire (LLQ) which was administered via survey to university and college level students. While LLQ responses may provide an indication of the individual's inclination towards LL attributes - such as "ability to locate required information", as a self-report instrument, it does not provide direct or tangible evidence of LL. Similarly, O'Neil et. al., 2015 [6] assessed life-long learning via a survey given to first year students who were enrolled in an introductory core course. The survey was based on students' self-reporting on their own engagement and the level of learning they developed. Others attempted to incorporate the skill of self-education within their engineering courses specifically in design courses, along with self-reporting via an end of course survey, as per Mouros (2003) [5]. Relying on capstone or design project reports can be problematic as submissions are often teambased thereby precluding individual assessment. It is easy to associate life-long learning with a project delivered in a course, where students are at close proximity to academic advice and supervision. The approach of this pilot study is to assess the ability of students to seek credible sources of information while away from the academic environment and its conventional instructor-based support.

Within traditional engineering education, students are challenged to fill in their knowledge gaps multiple times in their academic journey, through course projects, design projects, capstone courses...etc. While on campus, students practice seeking credible references to complement their knowledge with the support of their academic lecturers and teaching assistance who provide guidance and feedback. Arguably, an instructor intervention is a coached approach to life-long learning. A more authentic measure is when the student is seeking technical knowledge while away from the academic environment.

This paper presents preliminary work on creating a metric for assessing LL indicators using academic citations in technical reports, specifically work reports. Work reports are prepared by the students after they finish a work term as part of a co-operative education (co-op) program. A technical work report covers the work experience with the focus on design, analytical methods and data analysis. 
It is posited that if students can demonstrate competence in seeking credible technical information to fill in or support their knowledge when away from campus, then a program may more confidently claim the fostering of lifelong learning attributes.

\section{APPROACH}

At the University of Waterloo, the co-op program is a major component of the undergraduate engineering degree. Students must successfully complete five (5), 4month work terms during their 4-year academic program (12 terms). Students are required to submit three technical reports (work term reports). The reports must incorporate a situation of concern encountered during their work term, the engineering approach taken to address the situation, the appropriate engineering design and/or engineering analytical methods applied. It also must include data analysis, discussion, as well as logical conclusions drawn, and defensible recommendations put forward to advance the work place project. The reports are submitted during academic terms in the $2^{\text {nd }}, 3^{\text {rd }}$ and $4^{\text {th }}$ year. Students are asked to adhere to a specified technical report style manual, which includes citations and references using either APA or IEEE formatting. While the style manual provides some general guidance as to the use and format of technical citations, students must independently make decisions as to how they will gain and use credible [3] technical references within the report.

\subsection{Life Long Learning Indicators}

In keeping with $\mathrm{CEAB}$ expectations, University of Waterloo's Faculty of Engineering established three indicators for lifelong learning (LL1, LL2, LL3). However, the Biomedical Engineering Program under Systems Design Engineering, added four more indicators to recognize that measuring lifelong learning is not an easy straight forward task. LL4 is selected from the extended list. The establishment of measurable indicators is part of a program's continuous improvement.

LL 1. Identify gaps in their knowledge, skills and abilities

LL 2. Obtain and evaluate information or training from appropriate sources.

LL 3. Reflect on the use of information or training obtained.

LL 4. Apply knowledge and skills to areas beyond the current course or program.

The hypothesis of the pilot study is that the attempt of the students to find appropriate technical references, for the design and analysis component of their work (LL-2), would show that they have identified the gaps in their knowledge beyond course material that they have learnt (LL-1). By proxy, it implies that the student has reflected upon the use of information (LL-3) and applied the pursued knowledge to their work experience LL-4). For this study, the quality of the technical reference reflects on the ability of the student to identify credible sources as specified in indicator LL-2. The other 3 indicators, LL-1, LL-3 and LL4 are indirectly covered by the student, but not directly quantified in this pilot study.

\subsection{Data Extraction and Analysis}

A sample of 12 senior ( $4^{\text {th }}$ year) students' work term reports was drawn from a cohort of 92 , and any personal identification was blinded to the analyzer (author) through redacting and by assigning file names $\mathrm{A}$ to $\mathrm{L}$. To examine the robustness of the LL-2 metric, the reports selected represented a range of technical writing competencies as well as industry sectors. References used by the students were carefully examined according to the following criteria:

a) Number of total references used in the report.

b) Number of technical references used in the design and analysis section, which will be referred to as (TR) in this paper.

c) Quality of each TR per student was evaluated according to a rubric shown in Table 1. Scores can range from 1 (below expectation) to 5 (exceeds expectation). Detailed rubric definitions are listed in Table 1. The rubric was developed by the author based on the quality of reference as outlined by University of Waterloo Library [3]. The author also considered the effort that students put into seeking information. For example, if the student reached out to a text book that was assigned in a previous course, this is meeting expectations. On the other hand, if the student reaches out to other textbooks, or peerreviewed journal papers, then the student would have exceeded expectations. If the student is relying on references provided by their employer, then the student did not put an effort into seeking the information. If the reference is commercial (e.g. product website, blog advice), then the reference levels is sitting at low to marginal expectations.

Note: that the rating of " 3 " spans across two categories, reflecting a suspected convenience factor. The reference is acceptable but could likely be improved. 
Table 1: Technical Reference (TR) Quality Level Rubric

\begin{tabular}{|c|c|c|c|}
\hline $\begin{array}{c}5 \\
\text { (Exceeding } \\
\text { Expectation) }\end{array}$ & $\begin{array}{c}4-3 \\
\text { (Meeting } \\
\text { Expectation) }\end{array}$ & $\begin{array}{c}3-2 \\
\text { (Marginal } \\
\text { Expectation) }\end{array}$ & $\begin{array}{c}1 \\
\text { (Below } \\
\text { Expectation) }\end{array}$ \\
\hline $\begin{array}{l}\text { 5-Student used } \\
\text { text book that } \\
\text { not necessarily } \\
\text { assigned in a } \\
\text { course with } \\
\text { detailed } \\
\text { reference to the } \\
\text { section in the } \\
\text { book } \\
\text { e.g. page \# }\end{array}$ & $\begin{array}{l}\text { 4-Student used } \\
\text { a text book that } \\
\text { is assigned in a } \\
\text { course and } \\
\text { referred to the } \\
\text { exact section. }\end{array}$ & $\begin{array}{l}3 \text {-Student used } \\
\text { a website } \\
\text { reference that } \\
\text { is credible. [2] }\end{array}$ & $\begin{array}{l}\text { 1-Student } \\
\text { used a } \\
\text { website that is } \\
\text { less credible } \\
\text { e.g. business } \\
\text { website. }\end{array}$ \\
\hline $\begin{array}{l}\text { 5-Student used } \\
\text { a peer reviewed } \\
\text { journal paper. }\end{array}$ & $\begin{array}{l}\text { 3-Student used } \\
\text { a research } \\
\text { reference that is } \\
\text { not peer } \\
\text { reviewed e.g. } \\
\text { conference } \\
\text { papers or } \\
\text { university } \\
\text { research open } \\
\text { access source. }\end{array}$ & $\begin{array}{l}\text { 2-Student used } \\
\text { job reference } \\
\text { that is given to } \\
\text { them by their } \\
\text { supervisor }\end{array}$ & --- \\
\hline
\end{tabular}

\section{RESULTS AND DISCUSSION}

\subsection{Results}

The total number of references (any) included in the technical reports ranged from 5 to 96 ; while the total number of TRs within the reports ranged from 1 to 17 . Across the 12 reports there were a total of 55 TRs with an average TR quality of 2.5 (Standard Deviation of 1.5 ). If the reports sampled are reflective of the students' cohort, then the average level of TR quality included in the work reports for the cohort lies between 2.1 and 2.9 (95\% confidence level).

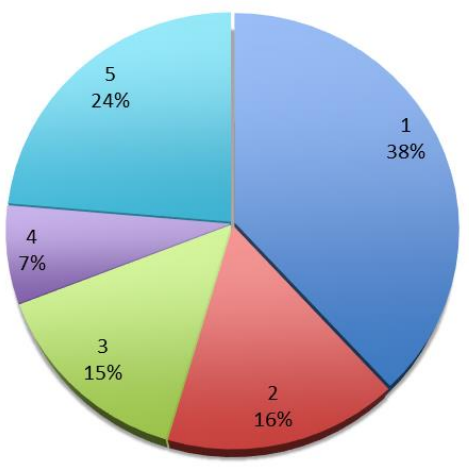

Figure 1: Total Technical Reference (TR) Levels

As presented in Figure 1, TR quality for the 12 reports were aggregated and analyzed for proportion of quality levels. More than half of the references (54\%) were on the low side of quality (levels 1 and 2), in that the references were either commercial websites or the references were internal to the organization, therefore, impossible to verify their quality. Approximately $30 \%$ of the references were competent, at levels 4 and 5 , where the students reached out to an appropriate domain, textbook or a journal paper.

Figure 2 presents results at the level of individual reports, highlighting that 8 of the 12 students used $50 \%$ or less of their references in the technical section. One student (student G) only included references in the technical section and those were of low quality (average level 1.6). Comparatively, students I and $\mathrm{K}$ used $27 \%$ and $4 \%$, respectively, of their references in the technical section; and all of those references met the criteria for the highest caliber (level 5). Student K used the largest number of total references (96); but most reference citations occurred in background sections. It is worth noting that student K's work term was at an academic institution, while the other students were in industry.

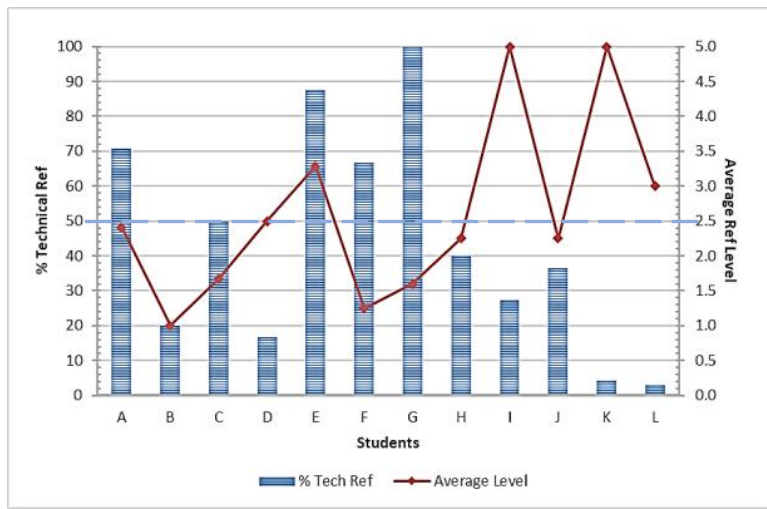

Figure 2: Percent of Technical References (TR) \& Average Level

Figure 3 shows the percent of TR quality levels used by each student. Excluding students, I and K, mentioned earlier, it is noted that only one student restricted references to level 3 , which is equivalent to a credible website that is not commercial, nor a direct referral to internal documents. The other 9 students (75\%) included low level quality references (levels 1 and 2) and about 33\% of the students exclusively used low level, as in students B, $\mathrm{C}, \mathrm{F}$ and $\mathrm{G}$ 


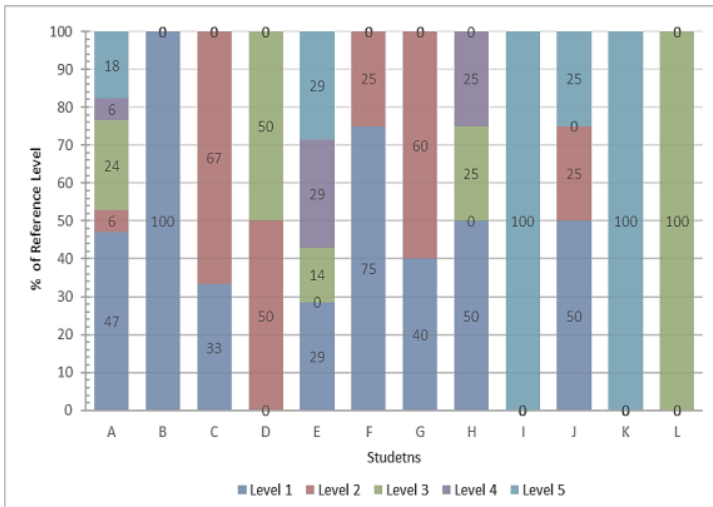

Figure 3: Reference Level Distribution per Student.

Using Table 1 to set reasonable benchmarks, a student demonstrating competence in LL should be selecting and using technical references that produce an average TR quality value of at least 3.0. In this sample of 12 , only 4 reports met or exceeded expectations; while another 4 fell clearly below expectations. Thinking in terms of completion rates (those that meet or exceed expectations), with $95 \%$ confidence, the expected proportion of the cohort (92 students) demonstrating LL via technical references is approximately 0.36 (using an Adjusted-Wald method the confidence interval ranges from 0.14 to 0.61 ) [7].

\subsection{Discussion}

Given that the purpose of this study was to pilot a potential metric for Life-Long Learning and that a small sample was drawn to reflect a range within a cohort, a conservative interpretation of the results is adopted.

From a Graduate Attribute perspective, it was encouraging to find that all 12 students reached out for references to include in the design and analysis sections related to their work; and did so while away from the academic term. It is worth mentioning that while including references is an academic requirement of work report evaluation, students did not receive guidance on where and how to use references in work term reports. A student could have met the referencing requirement by restricting reference use to the introduction or background sections of their report. The fact that all students within the sample did include at least one technical reference suggests that students are incorporating LL into their work experiences, even if weakly.

Of interest from a LL perspective is the fact that while all students seem to understand the need to reach out for domain-industry specific knowledge, approximately onethird of students relied exclusively on "convenience" references (i.e. commercial websites). Respecting that a small sample was drawn for this pilot and applying a conservative average TR quality value of 3.0 as a benchmark for meeting expectations for LL-2 (i.e. obtain and evaluate information or training from appropriate sources), it is estimated that approximately one-third of the senior cohort meets or exceeds the benchmark (using Adjusted-Wald method).

Within the sample, the majority $(75 \%)$ were relying on commercial references (level 1) or internal organizational documents (level 2). The fact that seeking information is available on multiple, portable devices may have made it easy for students to fall into the trap of collecting information from readily accessible, but potentially untrustworthy commercial references (e.g. blogs, product reviews). It is unclear if selecting lower quality references was done simply out of convenience, or because the student believes those reference types to be sufficient for their industry sector. Similarly, while there were students who consistently chose high quality technical references, it is unclear if those students did so because they were drawing from learning on their academic terms or following expectations of their supervising employers. A logical next step for this pilot study is to conduct follow-up interviews with the students to probe rationale for reference selection as it relates to academic expectations as well as their understanding of best practices in industry sectors. Ideally, interviews with employers should be added to better understand the type of guidance around seeking technical knowledge and credibility of sources that students typically receive within different industry sectors.

For the sake of continuous program improvement, the pilot study has helped to set a framework for carrying out a more thorough analysis of the entire cohort. A review of the remaining work reports of the cohort is needed to judge the accuracy of the current LL-2 completion rate estimate of approximately $36 \%$ based on the sample (12 from a cohort of 92). If the small sample approach proves to be reasonable, then it will serve as a strategy for evaluating future cohorts.

Ideally, a longitudinal approach would be established to allow for LL-2 assessments throughout the program (Year 1 to Year 4), with focus on individual student assessments through work reports and design courses. Such an approach would be in keeping with Candy P. (1991) [1], who identifies LL as a skill that needs to be developed in students, so they carry on self-education after finishing their formal education.

\section{CONCLUSION}

Life Long Learning in simple terms is to equip the students to independently seek and advance their knowledge in a world that is constantly changing. LL is not an easy attribute to measure, in that it is tied to the individual's personal value of LL, and exposure to best practices through academic and work experiences. Since Engineering is one of the critical professions that directly affects the public, it is important to find ways to monitor and assess student ability to seek reliable, competent information relating to the work place (i.e. away from 
academics). Assessing technical reference quality as a LL metric has theoretical promise over reliance on student self-reports. Assessing technical reference quality contained in individual student work reports has practical promise over reliance on academic-based work. For future work and validation, similar analysis could be developed in regular course assignments and design projects.

If the sample analyzed is reflective of the larger cohort, then most students understand the need to reach out for more technical knowledge; however, only one-third are meeting expectations where technical references are concerned. For the betterment of the profession and the public, preparing and guiding students as future engineers to seek credible, domain-specific information must be incorporated, assessed, and reinforced in the education system and the work place.

\section{Acknowledgements}

Authors are grateful for the support of the Department of Systems Design Engineering at the University of Waterloo for funding this work and participation in CEEA2018 conference. We acknowledge the prior work on Life Long Learning indicators developed by the Engineering Graduate Attribute Lecturer team; as well as Maud Gorbet, Director of Biomedical Engineering.

\section{References}

[1] Candy, P. (1991). Self-Direction for Lifelong Learning, A Comprehensive Guide to Theory and Practice", San Francisco: Jossey-Bass, 567pp. \{ISBN: 1-55542-303-5\}

[2] Engineers Canada Consultation Group-Engineering Instructions and Accreditation, (January 07, 2016), Graduate Attributes http://engineerscanada.ca/sites/default/files/GraduateAttributes.pdf, Accessed: December 26, 2017.

[3] Evaluating Information Sources: Websites. http://subjectguides.uwaterloo.ca/c.php?g=695510\&p=4931 748, Accessed: December 13, 2017

[4] Kirby, J. R., Knapper, C., Lamon, P., \& Egnatoff, W. J. (2010). Development of a scale to measure lifelong learning. International Journal of Lifelong Education, 29(3), 291-302. doi:10.1080/02601371003700584

[5] Mouros, N. (2003). "Defining, Teaching and Assessing Lifelong Learning Skills", 33rd Annual Frontiers in Education. FIE 2003., , pp. T3B-14-19 Vol.1. doi: 10.1109/FIE.2003.1263325

[6] O’Neil, T., Deacon, A., Larson, N., Hoffart, G., Brennan, R., Eggermont, M., Rosehart, W. (2015), Life-Long Learning, Conscientious Disposition, and Longitudinal Measure of
Academic Engagement in Engineering Design Teamwork, Learning and Individual Differences, vol 39, pp124-131. doi.: 10.1016/j.lindif.2015.03.022

[7] Sauro, J. and Lewis, J.R. (2016). Quantifying the User Experience: Practical statistics for user research. Waltham, MA: Morgan Kaufmann, (2 ${ }^{\text {nd }}$ ed.), 350pp. \{ISBN: 978-0-12802308-2\} 